\title{
VOZES EM MOVIMENTO: OCTAVIO PAZ E SOR JUANA INÉS DE LA CRUZ
}

Maria Esther Maciel

$U F M G$

para Haroldo de Campos

"As idades poéticas unem-se numa memória viva."

Gaston Bachelard

\section{RESUMO:}

Análise da leitura que Octavio Paz realiza da obra de Sor Juana Inês de la Cruz, como propósito de mostrar como o poeta mexicano, ao enfocar a autora barroca sob o prisma da modernidade, redimensiona sincronicamente o conceito de história e delineia a sua própria tradição poética. PALAVRASCHAVE:

Literatura Latino-Americana, Poesia Moderna, Barroco.

Desde o advento do modernismo hispano-americano em fins do século XIX, muitos escritores do nosso continente fizeram do "cosmopolitismo" uma via alternativa não apenas para a conquista da modernidade estética, como também para a construção de uma suposta "identidade" da literatura latinoamericana. 
Essa tendência, que se afirmou com os movimentos de vanguarda da América Hispânica no início do século XX e com o modernismo brasileiro de 1922, teve na "diáspora" de escritores latino-americanos rumo às grandes cidades modernas da Europa o seu motor principal, embora, como pondera Jorge Schwartz, muitos autores de grande dimensão universal e "verdadeiros cosmopolitas do ponto de vista de sua produção textual" não tenham vivido concretamente a aventura do desterro'. Do que se depreende ser o termo "cosmopolitismo" mais flexível do que o campo topológico sugere, uma vez que pode ser tomado no sentido amplo de uma recusa dos limites culturais de uma dada nacionalidade, em prol de uma abertura a outras experiências vivenciais ou textuais advindas de outros territórios e culturas.

Mas o fato é que, oscilando entre o desejo de ingressar na aventura da modernidade deflagrada pelos europeus e a procura de um rosto para a literatura do seu próprio continente, até então considerada um ramo do modelo literário peninsular, muitos escritores latino-americanos concretizaram topologicamente a experiência cosmopolita, deixando seus países de origem em direção aos grandes centros urbanos europeus, especialmente Paris, cidade configurada por muitos como uma "maneira dialética de dizer não à metrópole"? uma via alternativa de se sair da América sem se render ao topos do colonizador. Lá, apropriaram-se das estéticas de ruptura da modernidade européia e as reinventaram dentro das línguas espanhola e portuguesa, conjugando-as com a busca das tradições americanas do passado pré-colonial. Conseguiram, pela via do diálogo e da assimilação crítica da diferença e da alteridade, colocar a literatura latino-americana no fluxo da história moderna e, ao mesmo tempo, realizar uma ruptura do modelo europeu de modernidade.

Pode-se dizer que esse desenraizamento se fez em direçōes variadas. Se, num primeiro momento, o processo antropofágico de assimilação de alteridades apresentou-se basicamente em relação à estética de vanguarda européia, os rumos desse processo ampliaram-se na medida em que o interesse pelo "outro" se estendeu a outras tradições, advindas tanto do passado nacional de cada país latino-americano, quanto das civilizações orientais ou das culturas marginalizadas do Ocidente. A tradição do barroco hispânico, as manifestações culturais pré-colombianas e pré-cabralinas, as culturas negra e mestiça, as expressões da estética e da mitologia orientais, dentre outras, passaram a compor o intrincado imaginário poético latino-americano deste século, aliadas às

1. SCHWARIZ, 1993. P. 6

2. RIVAS, 1993. p. 104 experiências de ruptura de nossa modernidade estética, também marcada pela pluralidade e pela contradição. Do que resultou uma literatura híbrida e em descontínuo movimento rumo a uma identidade cada vez mais repleta de singularidades dissonantes. Literatura que, embora pertencente a um continente de precária modernização econômica, vem, por um processo de transculturação recíproca, alterando sensivelmente não só os rumos da literatura e do pensamento europeus, quanto o próprio conceito de "universalidade", tradicionalmente circunscrito à produção literária dos grandes centros culturais do ocidente.

Nesse sentido, muitos dos autores que se empenharam em construir uma imagem prismática da América Latina, à luz da alteridade e da diferença, continuando e inovando o legado de seus precursores do início do século, chegaram até memo a conquistar um espaço canônico no âmbito da literatura universal, como fica patente nos casos de Jorge Luis Borges, Julio Cortázar, Lezama Lima, Alejo Carpentier e Octavio Paz, dentre outros.

Não obstante essa "canonização" se restringir a autores deste século, a própria atuação de alguns desses autores no espaço privilegiado do reconhecimento internacional - e aqui me detenho no exemplo específico de Octavio $\mathrm{Paz}$ - tem contribuído para a revitalização e a divulgação, fora dos domínios de nosso continente, de outros escritores latino-americanos do passado, alguns injustamente colocados à sombra de astros cultuados pela historiografia tradicional. É o caso do trabalho que o poeta realizou sobre a obra da monja barroca mexicana Sor Juana Inés de la Cruz e que culminou no livro Sor Juana Inés de la Cruz o las trampas de la fe, publicado em 1982.

Paz, que sempre manteve uma relação dialógica com a tradição, preferindo lê-la sob o prisma da idéia do novo, vai, nessa obra, construir e divulgar para o mundo uma Sor Juana que se destaca tanto no contexto da literatura barroca de língua hispânica quanto no cenário da moderna poesia ocidental. Além de criar para si mesmo, enquanto poeta e pensador, a sua precursora latino-americana que, enquanto tal, nada fica devendo aos modernos poetas europeus que compõem o amplo "paideuma" paziano, visto que o próprio poeta a compara a eminentes representantes da "tradição da ruptura", como Mallarmé e Valéry.

Assim, com o duplo intento de explorar suas próprias raízes e retraçar - por uma via cosmopolita e não linear — a tradição poética hispano-americana em relação à história da moderna poesia ocidental, o escritor mexicano percorre com olhos de poeta e leitor do século XX toda a complexa estrutura do México colonial do século XVII. Em ritmo espiralado e marcado por idas e vindas 
temporais, ele conjuga as duas épocas a partir de uma abordagem simultaneamente sincrônica e diacrônica, na qual americanismo e universalismo também se destacam enquanto instâncias não excludentes.

Sem deixar de fazer uma radiografia completa do imaginário setecentista da Nova Espanha, Paz nos oferece uma Sor Juana diferente daquela dos manuais de literatura, acostumados a apresentá-la como um satélite privilegiado de Gôngora. Isso, porque o pensador mexicano se recusa a confinála nos limites de seu tempo, já que, segundo ele, Juana Inés, sem deixar de ter incorporado criativamente todos os procedimentos estéticos da era barroca e as tendências filosóficas da época (ultrapassando assim os limites geográficos e culturais de seu continente), antecipou certas inquietações próprias dos poetas modernos hispano-americanos e europeus. Ou, nas palavras do autor, ela "expresa a su época y, simultaneamente, es su excepción"3.

Esse caráter de exceção que marca o percurso da escritora se evidenciaria em vários níveis. Começando pela aguda consciência que teve de sua condição feminina, num contexto de forte repressão moral, em que à mulher era vetado o acesso aos livros e à vida intelectual. Sor Juana foi além dos limites a ela impostos pela vida reclusa do convento, pelos cerceamentos ideológicos da Igreja e da sociedade do tempo, assumindo abertamente o seu perfil de poeta versátil e de estudiosa aplicada, capaz de incursionar com desenvoltura por várias formas poéticas e campos interdisciplinares do saber. Além disso, a prática da auto-reflexão, da sondagem crítica de seu próprio percurso intelectual, destacase como fator que a distingue visivelmente dos seus contemporâneos. É nessa perspectiva que a carta intitulada "Respuesta a Sor Filotea de la Cruz" pode ser tomada como um texto exemplar, por revelar, como apontou Paz, uma poeta que "puso sus dones intelectuales al servicio del análisis de sí misma", à feição de um Valéry - que levou até as últimas consequiências a lúcida tarefa de se auto-investigar.

Octavio Paz, não obstante examine as semelhanças entre a estética barroca à qual a poeta se filiou e as estéticas de ruptura próprias da modernidade, o que poderia dar margem a se pensar que o que ela tinha de moderno era o que nela havia de mais barroco, vai mais longe ao marcar a dissonância entre a monja (que teria prenunciado a "modernidad más moderna") e seus contemporâneos. Para isso, elege o poema Primero Sueño para explorar com mais detalhes a relação de "simetria dissonante" de Sor Juana com a própria estética barroca, marcando também, indiretamente, com tal trabalho de

$$
\text { 3. PAZ, 1982. p. } 500
$$

investigação, a marca diferencial dos poetas modernos em relação aos poetas barrocos: a que se refere à questão da consciência crítica e autocrítica, da razão que se destrói a si mesma.

Ao tomar o Primero Sueño como o cerne da diferença entre Sor Juana e os principais poetas do seu tempo, Paz, de alguma maneira, reedita e desenvolve as considerações feitas por outros estudiosos do barroco ou da literatura mexicana, como Alfonso Reys e Lezama Lima, que também privilegiaram o mesmo poema como centro irradiador de toda a obra da escritora. $O$ primeiro, ainda que admitindo a existência no texto de ecos formais de Gôngora, conferelhe uma modernidade análoga à de certos procedimentos de Proust, dos surrealistas e de Valéry"; enquanto o segundo, em suas incursões no que chama de "curiosidade barroca", descarta a dívida desse poema para com as Soledades de Góngora e o compara aos Sonetos de Orpheu, de Rilke, ao Narciso, de Valéry e ainda ao Muerte sin fin, de Gorostiza'.

Paz, como Reyes, não subtrai as afinidades do poema com a estética gongórica, sobretudo no que tange à sua superfície emblemática, atravessada de latinismos, alusões mitológicas, hipérbatos e imagens, extraídos do universo labiríntico do poeta cordobês. Mas adverte: "las diferencias son mayores y más profundas que las semejanzas". E, para trabalhar esses rasgos distintivos, não apenas menciona - como Lezama Lima - as similitudes do poema com o Muerte sin fin de Gorostiza ou as suas afinidades com o Altazor de Vicente Huidobro, mas também mergulha no sinuoso mundo de imagens e conceitos do Sueño de Sor Juana, para enfatizar tanto o caráter intelectual, crítico, do poema, quanto a sua geometria de sombras e claridades súbitas. Enquanto, segundo ele, Góngora se vale de um leque verbal de cores e resplandescências, a poeta mexicana opta pela penumbra, numa viagem noturna que culmina no encontro com o abismo e com a consciência do nada.

E é exatamente nesse ponto abismal que o poema se configuraria, surpreendentemente, como uma antecipação do Un coup de dés de Mallarmé, poema que enfoca o vộo solitário do espírito humano pelos espaços estelares, um vôo que também culmina na queda e na contemplação do vazio.

Nas palavras de Octavio Paz:

El parecido es más impresionante si se rapara en que los dos viajes 
terminam en un caída: la visión se resulve en no-visión. El mundo de Mallarmé es el de su época: un cosmos infinito o transfinito; aunque el universo de Sor Juana es el universo finito de la astronomia ptolomaica, la emoción intelectual que describe es la de un vértigo ante el infinito. Suspendida en lo alto de su mental pirámide hecha de conceptos, el alma encuentra que los caminos que se le abren, son abismos y despeñaderos sin fin. En Primero Sueño aparece un espacio nuevo y distinto, desconocidolo mismo por fray Luis de Leon y los neoplatónicos del XVI que por los poetas del XVII, Quevedo, Góngora o Calderón. ${ }^{6}$

Paz sonda, com detalhes, as configurações desse novo espaço. Para isso, incursiona primeiramente na cosmografia dos séc. XVI e XVII, buscando, sobretudo na obra do jesuíta alemão Atanasio Kircher, através da qual Sor Juana teria se enlaçado à tradição hermética já arruinada pelo advento do cartesianismo e da astronomia newtoniana, os elementos constitutivos do universo cósmico do Primero Sueño.

Kircher, afeito à lógica das correspondências universais entre religiões e culturas de vários tempos, aliou o catolicismo sincretista não apenas com o hermetismo neoplatônico, mas também com as novas descobertas astronômicas de Copérnico e Galileu. Além disso, buscou na civilização egípcia a resposta para os enigmas da história. Como ressalta Haroldo de Campos, citando Joscely Godwin, "Kircher, com seus diagramas místicos, suas cartas herméticas e suas pranchas alegóricas" tinha uma obra "variadamente abeberada na "sabedoria egípcia, na teologia fenícia, na astrologia caldéia, na cabala hebraica, na magia persa, na matemática pitagórica, na teosofia grega, na alquimia árabe e na filologia latina"?

O contato de Sor Juana com a vasta diversidade do pensamento kircheriano teria possilibilitado a ela imaginar um universo que, embora remeta aparentemente à concepção ptolomaica, descortina espaços vertiginos, só bem mais tarde vislumbrados esteticamente pela poesia moderna. A presença de duas pirâmides opostas como base alegórica do poema, bem como as recorrentes evocações de figuras da mitologia egípcia também apontariam para a afinidade intelectual da monja mexicana com as idéias prismáticas do padre alemão, ainda que ela tenha acrescentado a esse legado uma visão particular, produto de uma

6. PAZ, 1982. p. 471.

7. CAMP05, 1995. p. 7 consciência mais cindida, mais abismal (e, portanto, moderna).

Diante dessas relações simultâneas de correspondência e divergência entre Sor Juana e Atanasio Kircher, ou Sor Juana e estética barroca, Paz movido por uma lógica de associações em cadeia, própria do método analógico - passa a aproximar a monja mexicana, enquanto poeta, de Mallarmé, que, além de ter também assimilado procedimentos estéticos barrocos, recolheu criativamente os ensinamentos do hermetismo neoplatônico de feição alquímica (o que o avizinha de Kircher), visíveis no projeto de construção do Grande Livro - espécie de duplo verbal do universo. Só que, como se sabe, Mallarmé, movido pela consciência irônica (obviamente bem mais aguda e radical que a de Sor Juana), não vislumbrou esse universo como uma ordem, mas como um "céu constelado de vazios", para usar aqui uma imagem de Blanchot. Un coup de dés seria, portanto, uma reprodução visual desse espaço, ao se mostrar como um todo estilhaçado, onde brilha menos a palavra do que o silêncio. É nesse sentido que Mallarmé encena no poema a irrealização de seu próprio "ideal desproporcionado" rumo ao Grande Livro, já que este não existe senão enquanto o duplo da "neutralidade idêntica do abismo".

Como mostra Paz, Primero Sueño alegoriza igualmente um fracasso: o da alma humana que, desvencilhada do corpo durante o sono, alça seu "vôo intelectual" pelas esferas supralunares, à procura do conhecimento, e que, ao se deparar com uma visão intensamente luminosa, despenca, ofuscada. Movida pelo desejo de continuar sua aventura, resolve subir sozinha a grande pirâmide de conceitos, mas se vê impedida pelo surgimento do sol e pelo despertar do corpo. Como resume Octavio $\mathrm{Paz}$, "el poema es el relato de una visión espiritual que termina en una no-visión", ou seja, apresenta alegoricamente, "la revelación de la no-revelación", o que contraria os princípios místicos predominantes no seu séculos.

Paradoxalmente, essa insólita não-revelação é associada, pelo autor, a uma outra espécie de revelação: a consciência de que o fracasso é um saber. Consciência esta inerente ao pensamento moderno e que se faz ver de maneira radical no poema de Mallarmé. Daí ambos os poemas terminarem, segundo $\mathrm{Paz}$, em pontos suspensivos, tendo como personagem invisível "el espírito humano, sin patria, frente al cielo estrellado".

Paz, entretanto, não menciona a diferença fundamental de Sor Juana em relação a Mallarmé: enquanto ela se vale de conceitos e alegorias para externar

$$
\text { 8. FAZ, 1982. p. } 505 .
$$

Disponível em http://www.letras.ufmg.br/poslit
REVISTA DE ESTUDOS DE LITERATURA
Belo Horizonte, v. 4, p. $39-47$, out. 96 
a sua consciência do abismo, esta se encontra materializada, em Un coup de dés, na própria disposição gráfica das palavras e dos espaços brancos sobre a página, configurando o que Valéry chamou de um "espetáculo ideográfico de uma crise ou uma aventura intelectual". Primero Sueño, de 975 versos, é contínuo e flui ao ritmo das imagens de luz e sombra. A linguagem é nitidamente barroca e a topologia exibe contornos visíveis, sobretudo se tomarmos como paradigma de sua construção a figura das duas pirâmides de Kircher, reproduzida no Oedipus Aegyptíacus. No caso do poema da monja mexicana, o espetáculo ideográfico mencionado por Valéry vai se dar pelas vias da alegoria e do conceito.

Percebe-se que, nesse ponto, Octavio Paz prefere sondar as semelhanças entre os dois poemas, talvez com o propósito de realçar a excepcionalidade de Primero Sueño, considerado por ele um "poema barroco que niega el barroco, obra tardia que prefigura a la modernidad más moderna".

Paz chega até mesmo a detectar uma dimensão autobiográfica no texto, ao observar que, em meio à sua paisagem abstrata, atravessada de imagens delirantes e labirintos verbais, é possível ler a história de um tumultuado percurso intelectual: o da busca apaixonada do conhecimento, a mesma que a autora traçou detalhadamente em Resposta a Sor Filotea, de 1690. Busca que, por transgredir as imposições e os cerceamentos sociais, só pôde se dar como uma viagem noturna, como um sonho que, na verdade, encobria uma "lúcida vigília".

O fracasso dessa busca, duplamente alegorizado no poema pelas imagens da queda da alma e do despertar do corpo, nos contaria, assim, sob a perspectiva paziana, "la história da crise intelectual de Sor Juana e el acto inicial de su conversión"lo. Proposição que não deixa de ser polêmica, considerando-se a distância temporal entre a escrita de Primero Sueño e a renúncia da monja à vida intelectual, em março de 1694."

De qualquer maneira, $\mathrm{Paz}$, através desse longo e intrincado percurso, que inclui um detalhado e monumental estudo biográfico da autora, constrói a sua Sor Juana, valendo-se de parâmetros que a situam como uma mulher de extrema atualidade dentro do cenário contemporâneo, mas que nem por isso deixou de viver intensamente a sua época. Ele revitaliza, assim, uma figura literária que, simultaneamente, encerrou uma tradição (a do barroco de língua

9. PAZ, 1982.p. 500.

10. PAZ, 1982. p. 498.

11. Emboro tenho sido publicodo pela primeiro vez no segundo volume dos Obros, em 1692, o poema já oparece, como refereencia, no Resposto o Sor Filoter . Segundo Octovio Poz, ele deve ter sido escrito por volto de 1685 . espanhola) e prenunciou outra, que só viria à tona quase dois séculos depois: a que teve seu auge na figura de Mallarmé e à qual também se filia o próprio Octavio Paz. Ou seja, o poeta mexicano, sustentando-se na conjunção entre tradição e ruptura, cosmopolitismo e americanismo, faz de Sor Juana Inés de la Cruz uma autora de dimensão, ao mesmo tempo, barroca e moderna, mexicana, hispânica e universal, que, portanto, é sempre outra, dependendo do ângulo do qual é vista e revista. E é na medida dessa mobilidade temporal e espacial que Paz vai também recriar, a partir da estética barroca de Sor Juana, a obra de Mallarmé e, por extensão, a sua pópria.

Como se vê, uma rede de vozes e contextos que se cruzam e se iluminam reciprocamente, configurando uma tradição poética e pluralizando o conceito secular de universalidade.

\section{ABSTRACT:}

This essay is an analysis of Octavio Paz' reading of Sor Juana Inés de la Cruz's writings in order to demonstrate how the Mexican poet redimensions sinchronically the concept of history and outlines his own poetic tradition as he studies her work in the light of modernity. KEYWORDS:

Latin-American Literature, Modern Poetry, Baroque.

\section{REFERÊNCIAS BIBLIOGRÁFICAS}

BLANCHOT, Maurice. Olivo por vir. Trad. Maria Regina Louro. Lisboo: Relógio d'Água, 1984 BORGES, Jorge Luis. Kofka y sus precursores. Obros completos I (1923-1972). Buenos Aires: Emecé, 1974. CAMPOS, Maroldo. A falo visivel do livro mudo. In: Follha de Söo Poula. SP, 03/09/95. (Suplemento Hais).

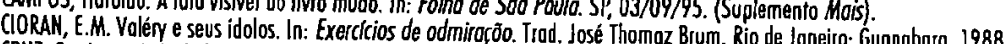
CRUZ, Sor Juana Inés de la Obras completess - tomo i. Méxicic: Fondo de Cultura Económica, 1988.

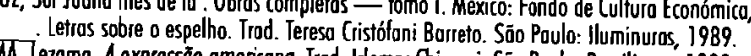
IIMA, Lezoma. A expresš̃öo omericana. Irod. Irlemar Chiampi. São Paulo: Brosiliense, 1988. MACIEL Morio Esther. As vertigens do lucidez: poesio e crfico em Octovio Poz. Söo Poulo: Experimento, 1995. MALARME, S. Igitur, Divogations Un coup de dés. Poris: Gallimard, 1976. PAZ. Octovio. Los peras del olmo. Bacelona: Seix Barrol, 1986 - Los hijos del limo. Barcelona: Seix Barral, 1989.

REVES Sor Juana de la Cruz o los trompas de lo fe . México: Fando de Cullusa Económica, 1982. REYES, Alfonso. Letros de la nuevo Espoño. In: Obros completos. Mexico: tomo 2, p. 377 .

RVAS, P. Paris como a copital literória da América Latino. In: CHIAPPINI, Lygia (org.). Literoturo e Hstória no América Lotina. Sũo robaYMa Andrés Éúncher Paro

SCHWARTZ, Jorge. Yonguardo e cosmopolitismo Sueño de Sor Juano Inés de lo Cruz. México: Fondo de Cultura Económica, 1990
Disponível em http://www.letras.ufmg.br/poslit
REVISTA OE ESTUDOS OE LITERATURA
Belo Horizonte, v. 4. P. 39- 47, out 96 